\title{
TERRITORIALIDAD Y MOVILIDAD HUMANA: ASIMETRÍAS DEL PROCESO GLOBALIZANTE EN EL COTIDIANO DEL INMIGRANTE BRASILEÑO EN ESPAÑA'
}

\author{
AMANDA REGINA GONCCALVES \\ Universidad Estatal Paulista, UNESP (Brasil).
}

\section{RESUMEN}

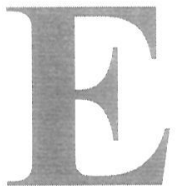

n el actual período de globalización, los movimientos migratorios tienen adquiridas nuevas formas y dimensiones, así como tienen sido renovadas las relaciones entre movilidad del capital, la humana y la territorialidad. Estas características son definidoras de la reestructuración que está viviendo la economía mundial y de la implementación generalizada de políticas económicas neoliberales. Esto remete a cuestiones relacionadas con las contradicciones entre aquellas relaciones, a la ciudadanía y a la integración social en una escala global.

Palabras clave: Brasil, España, inmigración, territorialidad, globalización.

\section{INTRODUCCIÓN: REFLEXIONES SOBRE LAS NUEVAS FORMAS Y DIMENSIONES DE LAS RELACIONES DE MOVILIDAD}

Un período excepcional de los anales de estudios de las migraciones en España evidencia el inédito crecimiento de la población de nacionalidad extranjera en España. Según Andreu Domingo y René Houle (2004, p. 1), de 1996 a 2003, se triplicó la población con permiso de residencia, excepcionalidad que trae consigo constantes cambios en las legislaciones y regularizaciones de los inmigrantes e implicaciones sociales en la población extranjera en situación irregular.

Las estadísticas españolas también revelan el papel cada vez más importante que desempeñan los ciudadanos provenientes de Brasil en esta sociedad.

1 Este trabajo fue posible gracias a la participación en el Programa de Cooperación Académica en Educación Superior entre la Unión Europea y América Latina, en el Proyecto Alfa-Trans-Migra-Red: Red para Investigación Transnacional y Transdisciplinar de las Migraciones durante el periodo de estancia científica en el Dpto. de Sociología II, Psicología, Comunicación y Didáctica, de la Universidad de Alicante (España), bajo la tutoría de Miguel Ángel Mateo Pérez, y de Élson Luciano Pires y Bernadete de Castro Oliveira en nuestra institución de origen. 
Actualmente, 7.412 inmigrantes brasileños forman parte legalmente de la nueva composición étnica de España (INE, 2004). A esta cantidad se suma otro gran número de brasileños no legalizados, donde están incluidos el $80 \%$ de los entrevistados para esta investigación, una parcela que, como muchos otros individuos no provenientes de países integrantes de la Unión Europea, tienen suscitado un intenso debate político en las más distintas instancias públicas y privadas de los países europeos, ya que su influencia en la sociedad se refleja de formas múltiples y diversas.

Utilizamos varios procedimientos etnográficos, como "entrevistas en profundidad" con inmigrantes brasileños en la ciudad de Alicante (Comunidad Valenciana), con el fin de recolectar testimonios envolviendo las rememoraciones de estos inmigrantes en lo que ellos dicen al respecto, a sus experiencias y trayectorias de vida, lo que permitió la captación inmediata y corriente de información sobre los más variados temas, sobretodo de los propios sujetos objeto de la investigación.

Destacamos en este texto fragmentos de entrevistas con seis brasileños, que poseen entre 26 y 35 años de edad, provenientes principalmente de las provincias brasileñas de Río de Janeiro, Minas Gerais, Goiás y Bahía y, actualmente, residentes en España, por un período de uno a seis años ${ }^{2}$.

Alicante, donde viven los inmigrantes entrevistados, es una provincia que pertenece a la Comunidad Valenciana, se sitúa en la costa mediterránea española, denominada "Costa Blanca". En 1994, ésta era la provincia con el mayor número de inmigrantes empleados en el sector de servicios, con un 77,3\% y la provincia que posee mayor porcentual de mujeres empleadas (Mateo Pérez, 2002). Actualmente, Alicante posee 316.178 habitantes, de los cuales 31.542 son inmigrantes reglamentados. Entre estos últimos, los brasileños resultan un total de 303, de los que $211(70 \%)$ son del sexo femenino (Ayuntamiento de Alicante, 2004).

Enseguida, daremos destaque a las miradas provenidas de los inmigrantes entrevistados sobre el contexto aquí planteado, buscando, así, dar significado a sus participaciones directas en las construcciones de las representaciones sobre el inmigrante brasileño en el territorio español.

\section{LAS CONTRADICCIONES DEL PROCESO GLOBALIZANTE EN EL COTIDIANO DEL INMIGRANTE BRASILEÑO EN ESPAÑA}

Los trabajos que los inmigrantes hacen son trabajos que no exigen papeles, lo que para los empresarios significa muchas ventajas. Es un capital social extranjero que, dentro de España, hoy, incluyendo los brasileños, él tiene una potencia económica muy fuerte, porque es una mano de obra que no necesariamente es barata, pero es más barata que la mano de obra española. Daniel, 35 anos, brasileño que vive En España.

2 Usamos pseudónimos para identificar a los entrevistados a fin de preservar la identidad de los mismos, ya que la mayoria no poseen los documentos (papeles) exigidos para residir en en el país. Cabe aclarar que los inmigrantes se refieren al visto de inmigrante e documentación para fines de legalización en el país, como "papeles". 
En el mundo de la globalización, el espacio geográfico gana nuevas definiciones e importancias porque en una situación de extrema competitividad la eficacia de las acciones está estrictamente relacionada con su localización, y el territorio como un todo revela los movimientos de fondo de la sociedad (Santos, 2000).

Seguro que su trabajo -es decir, la eficacia de su acción- sería más valorado en Europa. Jair vendió su pequeña empresa alimenticia, se endeudó y migró a España en busca de ingresos y mejores condiciones de vida. Según él:

Como nosotros no tenemos ingresos en Brasil, no tenemos acceso para crecer. Y como yo tenía conocidos que estaban aqui en Europa, ellos me miraban trabajar allá en Brasil aquello tanto, entonces ellos decian: Ah, en Europa, tú trabajando esto tanto, tú vas a mejorar tu situación.

JAIR, 32, COCINERO INFORMAL EN RESTAURANTE DE PROPIEDAD BRASILEÑA EN ESPAÑA, COMPARTE UN PISO DE DOS HABITACIONES CON SEIS BRASILEÑOS Y UN NIÑNO.

Desde un pueblo de la provincia brasileña Minas Gerais, Jair hace el trayecto más común de los inmigrantes brasileños, cuya narración (abajo) indica que el proceso de elección del país involucra varios criterios, siendo los más determinantes la economía y la lengua y, después, la cultura del país. Otro dice que la cuestión de la seguridad también es un determinante en la elección y permanencia en un pais. Son dimensiones como éstas, relacionadas con la estructura de un territorio, las que revelan la actual tendencia de un "proceso de compartimentación generalizada", donde se asocian y chocan el movimiento general de la sociedad planetaria y el movimiento particular de cada fracción, regional o local, de la sociedad nacional (Santos, 2000).

Mis ganas eran de quedarme en Brasil trabajando. Yo intenté mucho.

(...) Yo elegi España porque es un país de economía mejor que Portugal, porque nosotros hablamos portugués, pero las ganas, de verdad, era ir para Inglaterra o Bélgica, donde es mis rico, pero yo no hablo inglés, entonces, fijé que me adaptaria más a la lengua española. Vine para España.

Roberto Carlos, 28, ex-micro empresario en Brasil. Trabaja como albañal en España.

Aqui tú no tienes aquella paranoia (de los grandes centros urbanos brasileños) que tú puedes ser asaltado, que puede pasar algo contigo. (...) De una forma general, las personas eligen vivir aquí en España, por estas condiciones de vida, por la cuestión de la seguridad y, claro, por la cuestión económica. Cada persona tiene sus prioridades aquí.

almeida, 32 años, Mestre en Historia no Brasil. Trabaja como enfermero particular DE ANCIANOS Y COMO CANTANTE EN ESPAÑa.

Características como las descritas arriba también son consecuencia de procesos de antagonismos en las movilidades espaciales del capital y del hombre -cuyo principal atributo es la división territorial del trabajo-donde muchos actores no disponen de instrumentos de regulación que interesen a la sociedad en su conjunto, lo que conlleva a destituir colectividades (como la de los inmigrantes) del comando de su propio destino.

Esto conlleva el impedimento de decidir sobre su destino, en la medida que, como indican las narraciones, ellos tienen que abandonar su deseo de vivir y trabajar en su país de origen, para migrar a otro, aunque en este otro 
sitio no sea de su elección prioritaria, pues la lengua, cultura, seguridad o el régimen de visados impiden la movilidad deseada, y tampoco es de interés de los actores de los países desarrollados subsanar tales carencias con el fin de mejorar la integración social de los inmigrantes que allí viven. Lo mismo pasa con Milene, que es destituida de su derecho de retornar a Brasil, pensando en un posible retorno a España. Configurando, por lo tanto, un ejemplo de asimetrías de los procesos aquí estudiados, sumado a una constitución fragmentada del territorio.

La inmigración brasileña en el territorio español constituye un ejemplo de esa tendencia y un dato esencial en el entendimiento de la actual fragmentación del territorio y de la sociedad - en el territorio, las infraestructuras, servicios públicos y normatizaciones son direccionados a lugares específicos y en la sociedad son producidos guetos, situaciones de discriminación o hasta mismo de egoísmos locales o regionales exacerbados, justificados por la necesidad de defensa de las condiciones de supervivencia regional ${ }^{3}$.

Un argumento más taxativo a este respecto es el de Daniel, de 35 años, doctorando en la universidad pública española, "capoeirista" y cantante.

El discurso de la globalización es un discurso sin valor, porque, de hecho, los paises quieren que se globalice sólo el transporte de gran capital $y$, en los hechos reales, meten muchas trabas, cierran sus comercios, cierran sus fronteras, ponen dificultades. La Unión Europea es una Unión Europea sólo para los europeos y para más nadie.

DANIEL, 35.

La situación arriba descrita remonta a un mundo que, aunque más interconectado que nunca, donde los flujos financieros y de comercio parecen fuertemente liberalizados, la movilidad de los individuos aún enfrenta fuertes barreras, revelando asimetrías de una globalización que incluye individuos, poblaciones, países y regiones y, al mismo tiempo, excluye a tantos otros, donde, como apunta la CEPAL (Comisión Económica para la América Latina y el Caribe, 2004), "contrasta la elevada movilidad del capital con la restricción de los desplazamientos internacionales de la mano de obra (...) y las desigualdades en los niveles de desarrollo son determinantes en estos movimientos". Para esta institución, la migración internacional es un fenómeno multifacético que exige la adopción de medidas multilaterales, basadas en la cooperación entre los Estados, debiendo ser superadas las políticas unilaterales de los países, en vista de que hoy la legislación es mucho más restrictiva, orientada para un mayor control de la inmigración.

Esta realidad puede ser constatada en diversas hablas de entrevistados en la investigación de campo. Destacamos a continuación dos situaciones aparente-

3 Algunos movimientos de defensa regional -fomentados por todo un contexto histórico de la formación de los territorios, pero también depositando justificativas de defensa en el actual proceso migratorio- llegan a extremos como por medio de procesos independentistas, como, por ejemplo, los activos en las regiones de Cataluña y País Vasco, en España. Santos (2000, p.87) llama ejemplos como estos de "regiones-paises", en vista de que en esta tendencia de fragmentación territorial y también fragmentación de visiones interpretativas de problemas como este, cuyos enfoques son dados a la economía o política (con visiones particularistas y no totalizantes del facto nacional), generan actuaciones defensivas mismo que estas tengan de se dar a costo de la idea de integridad nacional. 
mente contradictorias que ejemplifican esta asimetría del proceso de internacionalización del mundo capitalista.

Si tú sales del país y quieres volver tú tienes que hacer otro pasaporte, tú tienes que arreglar una salida para poder volver. Entonces yo estoy prefiriendo esperar esta ley que facilitase la legalización de los extranjeros y ya ir, pudendo volver tranquilamente. (...) Es un derecho que está hasta previsto en la ley, que todo el mundo tiene derecho de ir e vir, este es un directo básico del ser humano. Y yo veo que esto directo no es bien así. Tú no tienes directo de ir y venir, porque si no yo ya tenía ido a Brasil. Porque yo estoy desesperada para volver un poquito. Lo mejor sería que cada uno tuviese condiciones de vivir como se debe en su país, porque es lo mejor que tú puedes tener en tu vida, porque ahí están tus raices, tu gente y todo esto.

Milene, 26, graduada en Odontologia en Brasil. Camarera informal y profesora de SAMBA Y CAPOEIRA EN ESPAÑA.

Yo creo que entre 50 brasileños, o cualquier inmigrante que sea, uno logra un trabajo fijo hasta conseguir los papeles. (...) Hay un poco de hipocresia, pues ellos también quieren a los inmigrantes. Si, porque trabajamos barato, trabajamos mucho y bien y por poco, porque hacemos el trabajo que ellos no hacen. Trabajamos en cocinas de restaurantes, trabajamos en la construcción civil. Ellos no los hacen. JAIR, 32.

Contradicciones como estas expuestas, cuando se intensifican, contribuyen a que el inmigrante piense en otra cuestión: el retorno. Analizando esta cuestión desde el cotidiano de uruguayos y brasileños en España, destaca el trabajo de Karina Boggio y del brasileño Leonardo Cavalcanti. Ellos analizan el fenómeno migratorio, especialmente la cuestión del retorno, desde una perspectiva que dice comprender el inmigrante como "un facto social total", que involucra tanto su historicidad, cuanto el cuadro estructural en que está la sociedad de emigración e inmigración (Cavalcanti y Boggio, 2004). Para ambos, esta es una doble mirada que posibilita profundar la experiencia migratoria, en particular, en lo que dice respecto al tema del retorno.

Fundamentados en entrevistas con inmigrantes brasileños en Barcelona y con grupos de origen de inmigrantes en Brasil, según estos autores, sobre la figura del inmigrante inciden ciertas representaciones en los grupos de origen, relacionadas con la imagen del héroe, como una persona que tiene conquistas, digna de elogios. "Muchos inmigrantes relatan el sueño de volver de forma triunfante, como el héroe que regresa con los logros desde el "paraíso". Esta situación se sostiene aunque sea sólo en apariencia. Eso se observa en muchos inmigrantes que se esfuerzan para alquilar coches, llevar regalos y relatar con exageración sus logros y su bienestar al volver a su país. Esta actitud ante al retorno, en general, les permite obtener el reconocimiento del grupo de origen, lo cual permite negociar el sentido de su emigración y de su ausencia" (Cavalcanti y Boggio, 2004, p. 7).

Sensibles a los cambios que ocurren en casi todas las esferas de la vida cotidiana, sujetos y grupos del país receptor de inmigrantes también construyen sus representaciones. En general, depositan en la inmigración la justificación de muchos problemas con los que se encuentran y que se intensifican cada día, 
como, por ejemplo, los relacionados con el empleo, la educación, el aumento de la criminalidad, del tráfico, etc., no se atentando al incapacidad, lo mismo la falta de políticas de habitación, educación y saneamiento básico para las clases populares en general, donde están incluidos la mayoría de los inmigrantes. Sencillos ejemplos citados por los entrevistados clarifican algunos pensamientos deterministas de autóctonos.

Una amiga mía estos dias estaba en el autobús, ella tiene unos 15 años, y entró una señora y le habló para ella levantarse del lugar para ella sentar, que "como ella salia de su país para venir ocupar plazas en el autobús". ROBERTo Carlos, 28.

Lo que me pasó por yo ser extranjero es aquello de ellos pensaren que tú viniste aquí y que vas tomar el trabajo de ellos. DANIEL, 35.

Entendemos que las representaciones de autóctonos son fuertemente vulnerables aquéllas representaciones que circulan intensivamente en los medios de comunicación, de carácter marcadamente eurocéntricos. De este modo, intentamos aquí abrir ventanas para un tratamiento de la movilidad humana no como un problema, sino como algo provocador de las "solidariedades étnicas o culturales, hasta las solidariedades sociales y profesionales" (Capel, 2002).

\section{CONSIDERACIONES FINALES}

Este texto trató de explorar, desde una investigación cualitativa, las pautas de movilidad de los inmigrantes brasileños en España en un contexto de cambios socio-económicos con una demanda de mano de obra barata y poco cualificada.

Lo analizado nos enseña que la rapidez e intensidad que viene asumiendo este flujo migratorio viene acompañada de contradictorias respuestas dadas por el ámbito público y por el privado. En efecto, por una parte, del propio modelo de desarrollo capitalista, que implica la necesidad de utilizar en algunos sectores y ámbitos de la actividad económica, mano de-obra barata, precaria y flexible, función en el mercado de trabajo sustancialmente desempeñada por los inmigrantes extranjeros. Por otra parte, el poder público responde a esta llegada maciza de inmigrantes básicamente a través de acciones legislativas y de seguridad, que tiendan a regularizar la situación de los que ya están y a impedir, seleccionar o controlar la llegada de nuevos inmigrantes.

Parte de esta situación que describimos, según Van Nieuwenhuyze (2004, p. 22), se debe "a una legislación que considera a los trabajadores extracomunitarios como inmigrantes temporales, y que convierte la inmigración en un sendero de obstáculos administrativos". Considerando las condiciones de supervivencia y búsqueda de regularización de los inmigrantes indocumentados, mientras los regularizados desean estabilidad y acumulación de capital, las teorías neoliberales parecen contribuir a un proceso de acentuación de esta situación, en vista de que la movilidad para trabajo ascendente no parece estar vinculada a la educación o a las habilidades y capacidades profesionales.

En resumen, las relaciones entre la movilidad del capital y la movilidad humana son, al mismo tiempo, contradictorias y complementarias, pues la in- 
migración sigue siendo una de las escasas opciones a la una movilidad ascendente, implicando condiciones de irregularidad y subcontrataciones pero, concomitantemente, es la solución y forman los actores productivos que atienden la demanda creciente de un mercado de trabajo segmentado de las tendencias macroeconómicas, donde son desconsideradas todas sus potencialidades de enriquecimiento económico, social, político y cultural para las sociedades de origen y receptoras.

\section{BIBLIOGRAFÍA}

CAPEL, H. "Las políticas de atención a las necesidades de los inmigrantes extranjeros de escasos recursos". Scripta Nova. Revista electrónica de Geografía y Ciencias Sociales, Universidad de Barcelona, vol. VI, N. 117, 1 de julio de 2002. http://www.ub.es/geocrit/sn/sn-117.htm

CEPAL (Comisión Económica para la América Latina y el Caribe). http://www.eclac.cl/cgi-bin. Visitado en $12 / 10 / 2004$.

CAVALCANTI, L.; BOGGIO, K. "Una presencia ausente en espacios transnacionales. Un análisis sobre la cuestión del retorno, a partir del cotidiano de uruguayos y brasileños en España". En: IV Congreso sobre la inmigración en la España: ciudadania y participación. Gerona (España): Universidad de Gerona, 2004.

DOMINGO, A.; HOULE, R. "La actividad de la población de nacionalidad extranjera en España entre la complementariedad y la exclusión". En: IV Congreso sobre la inmigración en la España: ciudadanía y participación. Gerona (España): Universidad de Gerona, 2004.

Instituto Nacional de Estadísticas Española (INE). http://www.ine.es/

MATEO PÉREZ, M.Á. "Sobre las necesidades insatisfechas: género y migraciones como factores de pobreza”. Papers. Barcelona: Universitat Autónoma de Barcelona, n.66, 2002. p. 93-115.

NIEUWENHUYZE, I.Van. "Análisis de la dinámica de incorporación de los inmigrantes senegambianos en el mercado de trabajo de Mataró". En: IV Congreso sobre la inmigración en la España: ciudadania y participación. Gerona (España): Universidad de Gerona, 2004.

Ayuntamiento de Alicante, Comunidad Valenciana - España. http://www.alicante-ayto.es/estadistica/home.html

SANTOS, M. Por uma outra globalização: do pensamento único à consciência universal. Rio de Janeiro: Record, 2000. 236p. 